\title{
Poly(2-Furyl)Methylenesulfide as a Resin to Uptake of Metal Ions from Aqueous Solutions
}

\author{
J. Damasceno*, C.A.T. Gomes, J. Rieumont, R. Sanchez \\ Polymer Section, Advanced Materials Laboratory, Center of Science and Technology \\ State University of the North Fluminense \\ 28015-620 Campos dos Goytacazes - RJ, Brazil
}

Received: November 27, 2000; Revised: January 10, 2002

\begin{abstract}
The polymerization of poly (2- furyl) methylenesulfide - POLYTHIOFURFURAL - was performed in an $0.36 \mathrm{~mol} / \mathrm{L}$ aqueous solution of furfuraldehyde, saturated by bubbling hydrogen sulfide for $2 \mathrm{~h}$ at different temperatures. The reaction product was thoroughly washed and dried at $40{ }^{\circ} \mathrm{C}$ under vacuum. Poly (2-furyl) methylenesulfyde is a yellow powder with a rather unpleasant odor. The polythiofurfural obtained $[-\mathrm{CH}(\mathrm{C} 4 \mathrm{H} 3 \mathrm{O})-\mathrm{S}-]$ is a furan with thiols end groups. These are active adsorption centers for metal ions. The polythiofurfural was soluble in acetone and chloroform and its yields attained $80 \%$. Morphological analysis by Scanning Eletronic Microscopy indicates a regular and dense surface in an interesting spacial arrangement. Preliminary isotherms adsorption studies indicate specific affinity forNi (II) and Co (II) and different capacity adsorption, 0.022 and $0.045 \mathrm{mmol}$ per gram, respectively.
\end{abstract}

Keywords: polythiofurfural, ion adsorption, furan resins

\section{Introduction}

The use of resins to uptake of specific metal ions from aqueous solution has been the subject of research effort. In particular, the metal industry, as the refining of some metals, takes place in strong acidic solution and the presence of other metals as impurities provokes remarkable disadvantages $^{1}$ and introduce an negative ecologic impact from residual industrial water.

The resins used, with this objective, should present two essencially features; stability in strong acidic solution and metal ions selectivity.

The structural and morphological knowledge achieved for furfuraldehyde resins, obtained by catalysis with Brönsted acids ${ }^{2}$ and their chemical stability to acids, insolubility in water and organic solvents and acceptable thermal stability ${ }^{1-3}$ together with a good gas adsorption properties with respect to Nitrogen and Carbon Dioxide ${ }^{4}$ (related to the presence of furan rings and carbonyl groups) is a good feature to be employed as resin to uptake of metal ions from aqueous solutions. Particulary, when introduce a thiol group, it could expand the potential of the furfuraldehyde resins.
Murroy and associates ${ }^{5}$, reported that the sulfur atom gave a strong affinity to $\mathrm{Ag}$ (I) and $\mathrm{Hg}$ (II), and suggested that polymers with thiol group are appropiated to uptake heavy metal ions. Tsuda \& Yamashita ${ }^{6}$, confirm the efectivity of thiol groups and their effectivity in acids conditions.

The present research is a preliminary study on the temperature effect on the synthesis of polythiofurfural and metal ion adsorption behaviour from aqueous solution.

\section{Experimental}

\subsection{Purification of furfuraldehyde}

The furfuraldehyde used for the polymerization was purified by distillation under low pressure $\left(10^{-1} \mathrm{mmHg}\right)$. The distillation was carried out until a transparent liquid was obtained and tested by liquid chromatography (HPLC).

\subsection{Synthesis of PTF}

This resin was prepared in an aqueous solution of furfuraldehyde $(0.36 \mathrm{~mol} / \mathrm{L})$ at different temperatures by saturation of the reagent by bubbling hydrogen sulfide at $40{ }^{\circ} \mathrm{C}$ through a glass capilary tube during $2 \mathrm{~h}$. A milky suspen-

*e-mail: jodamasceno@petrobras.com.br, sanchez@uenf.br Trabalho apresentado no $14^{\circ}$ CBECIMAT, Águas de São Pedro, Dezembro de 2000. 
sion was obtained, after coagulation at $\mathrm{pH}=4$ under stirring, by adding chlorhydric acid in a dropwise fashion. The reaction product was thoroughly washed with destilated water to neutralization. It was then dried at $40{ }^{\circ} \mathrm{C}$ under vacuum.

\subsection{Molecular weight measurements}

The measurement were performed from different temperature polymer synthesis in chloroform solution $(1 \% \mathrm{w} / \mathrm{v})$ after filtered on 0,45 Sartorious filters. The molecular weights of PTF were determined using a Lachrom MerckHitachi Gel Permeation Chormatography (GPC) system with refractive index detector and PS 4000, PS400, PS40 and PS4 Licrogel columns placed in series with exclusion limits $10^{6}, 10^{5}, 10^{4}$, and $10^{3}$ Dalton. Chloroform was used as eluent at a flow rate of $1.0 \mathrm{~mL} / \mathrm{min}$ and injection volumes of $20 \mu \mathrm{L}$ were used. Polystyrene standards (Merck) with narrow polydispersity were used for the calibration curve.

\subsection{Chemical stability of the resins}

The resins obtained were not degraded or dissolved by water. However it was soluble in chloroform and acetone. Most of them were partially or totally oxidaded in contact with air and sun light. The degradation occurs after several days at room temperature.

\subsection{Scanning electron microscopy}

Electron micrographs were obtained using a Zeiss 692 SEM operation at $15 \mathrm{kV}$ and $70 \mu \mathrm{A}$. The surface was coated with gold to obtain a $20 \mathrm{~nm}$ thickness.

\subsection{Metal analysis}

The analysis of the product by contact polymer and metal ion aqueous solution was carried out by atomic absorption with a Zeiss model AAS4 spectrometer using tritisol standard solutions (Merck) for all the ions in $1000 \mu \mathrm{g} / \mathrm{LHNO}_{3}$ for $\mathrm{Co}$ and $\mathrm{Ni}$. All operation parameters for the lamps were chosen according to the supplier specifications. Potassium chloride $0.1 \%$ was used as dissolvent in all runs.

\subsection{Uptake of metal ions in aqueous solutions}

Adsorption determinations were carried out using a staticmethod by pouring aweighted amount of the polymer $(100 \mathrm{mg})$ into a tube with of fixed volume $(20 \mathrm{ml})$ of the tritisol standard solution, for each ion, in the range of concentrations from 5-200 $\mu \mathrm{g} / \mathrm{L}$. Tubes were shaken at $150 \mathrm{rpm}$ and temperature kept constant at $35{ }^{\circ} \mathrm{C}$ for a time previously determined to reach equilibrium for each ion. Mixtures were filtered on filter paper Hardened 40 and kept at $10{ }^{\circ} \mathrm{C}$ before analysis. Buffers were prepared with sodium monophosphate and citric acid and they were used to prepare solution with different $\mathrm{pH}$ values.

\section{Results and Discussion}

\subsection{Yields of furfuraldehyde resins (Polythiofurfural)}

The poly (2-furyl) methylenesulfide was obtained as a yellow powder with a rather unpleasant odor as previously reported $^{7}$. When exposed to air for several days it turns darker due to oxidation effects.

The 2-furfuraldehyde will not homopolymerize because its thermodynamic parameters are not favorable ${ }^{8}$. This fact can not be minimized by kinetics factors. During the polymerization an unfavorable balance among the entropy diminution and the lower enthalpy values occurs. This was obtained in the transition of $\mathrm{C}=\mathrm{O}$ double bond to $\mathrm{C}-\mathrm{O}-\mathrm{C}$ single bond and its is an implicit polymerization characteristic. The $\mathrm{SH}_{2}$ employed as co-monomers could remove this thermodynamic limitation because they are able to make the carbonyl group a co-monomer group.

Preliminary studies of polymerization yields, with results between $30{ }^{\circ} \mathrm{C}$ and $60^{\circ} \mathrm{C}$, indicated that the best result could be obtained when the reaction temperature (2furfuraldehyde solution) was $40{ }^{\circ} \mathrm{C}$ (Table 1) This represents an increase in polymer yield from $45 \%$ (previously reported $^{3}$ ) to $80 \%$.

Although the thermodynamic behaviour $(\delta \ln K / \delta \mathrm{T}=-\Delta \mathrm{H} / \mathrm{RT})$ could justify an yield increase by positive temperature effect, the experimental results showed a probably ceiling temperature effects. This justifies a decrement of PTF molecular weight at $60{ }^{\circ} \mathrm{C}$. Furthermore, the $\mathrm{SH}_{2}$ effective concentration in the water solution (Table 1) had additional impact in the molecular weight. This concentration and dissociation grade decrease with temperature increasing and the chains number intitiate decrease with the molecular weight impact on the PTF.

The morphology of the PTF presented an interesting feature detected by SEM. The polymer obtained in the gasliquid interphase by bubbling $\mathrm{SH}_{2}$ is characterized by spheric geometry with an interesting spacial arrangement (Figs. 1,2) and diameters ranging between 1-2 microns. This observed particle geometry should be convenient for flow when it is used as packing material to uptake ions from solutions.

Table 1. Effects of temperature on the molecular weight and polymerization yield.

\begin{tabular}{lccc}
\hline Temperature $\left({ }^{\circ} \mathrm{C}\right)$ & 30 & 40 & 60 \\
Furfural solution $(\mathrm{mol} / 100 \mathrm{~mL})$ & 0.36 & 0.36 & 0.36 \\
Water solubility of $\mathrm{SH}_{2}{ }^{9}$ & 8.51 & 6.74 & 4.22 \\
$(\mathrm{~mol} / 100 \mathrm{~mL})\left(\mathrm{x} 10^{-3}\right)$ & & & \\
Experimental polymer yields $(\%)$ & 66 & 80 & 46 \\
Molecular weightMp (Dalton) & 16234 & 19520 & 10440 \\
\hline
\end{tabular}




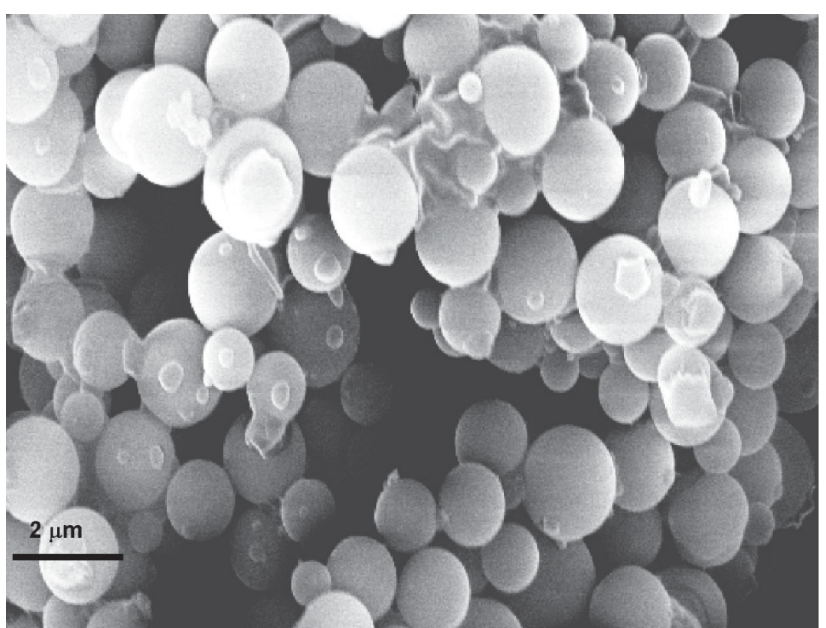

Figure 1. Electron micrograph of the dry polythiofurfural (6000X).

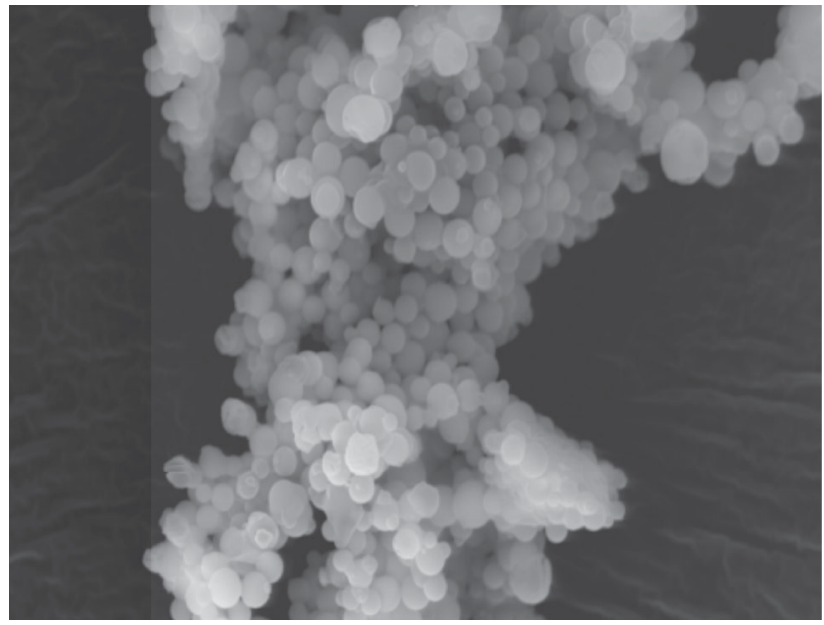

Figure 2. Electron micrograph of the dry polythiofurfural (2000X).

Table 2. Effects of the differents pHs solutions at $35{ }^{\circ} \mathrm{C}$, on the uptake for metal ions.

\begin{tabular}{lcccc}
\hline Metal ion & $\begin{array}{c}\text { Inicial solution } \\
(\mu \mathrm{g} / \mathrm{L})\end{array}$ & \multicolumn{3}{c}{$\begin{array}{c}\text { Amount } \\
(\mathrm{mmol} / \mathrm{g} \text { polythiofurfural })\end{array}$} \\
& & $\mathrm{pH} \mathrm{2.2}$ & $\mathrm{pH} \mathrm{4.0}$ & $\mathrm{pH} \mathrm{6.0}$ \\
\hline $\mathrm{Ni}^{2+}$ & 50 & 0.011 & 0.007 & 0.022 \\
$\mathrm{Co}^{2+}$ & 60 & 0.021 & 0.038 & 0.045 \\
\hline
\end{tabular}

Therefore, it seems that the interplay of some process parameters such as the interfacial tension and chemical reaction leads to this peculiar spatial arrangement. The dense surface of these spheres is smooth without appreciable porosity. Smoothness of polymeric microparticles has been attributed to the amorphous state of the polymer material, as has been already discussed ${ }^{10-11}$.

\subsection{Ion affinity from solutions}

As show in Table 2 the total capacity of polythiofurfural reached a maximum at $\mathrm{pH} 6.0$.

Thiol, acting on the end chain can be considered as an monodentate ligand but sulfur-oxygen complexation on the backbone could form a chelating ring ${ }^{12}$. Ligands in which $\mathrm{S}$ acts as a donor atom are soft Lewis bases (class-b) and oxygen is known as a ligand of class-a (hard bases). Furthermore, $\mathrm{Ni}^{2+}$ and $\mathrm{Co}^{2+}$ are considered acceptors that fall on the borderline of the soft-hard acid classification ${ }^{13}$. These cations form complexes with thiocyanate ions on the nitrogen (-NCS) (hard base). In particular, cobalt is able to complex either on the nitrogen or by the sulfur atom.

The above discussion seems to indicate that for the last hard cations, the oxygen of the furan ring does not participate in the complexation. For "hard acids", complexation with a hard base such as oxygen on a bidentate complex should promove appreciable adsorption and this was not actually observed. However, some common Lewis acids used as catalysts for cationic polymerization are known to form stable complexes with some furan compounds in homogeneous solution and some of them could be isolated at low temperatures ${ }^{14}$.

\subsection{Isotherm adsorption}

The experimental results could be fitting to Freundlich isotherm. Freundlich constants may be obtained from the intercept and the slope of the logarithm plot of the equation:

$[$ Ion adsorbed $]=\mathrm{k}$ [Ion concentration in solution at equilibrium $]^{\alpha}$

The isotherms shapes (Fig. 3) and Freundlich parameters (Table 3 ) shown different adsorbing ability for $\mathrm{Co}^{2+}$

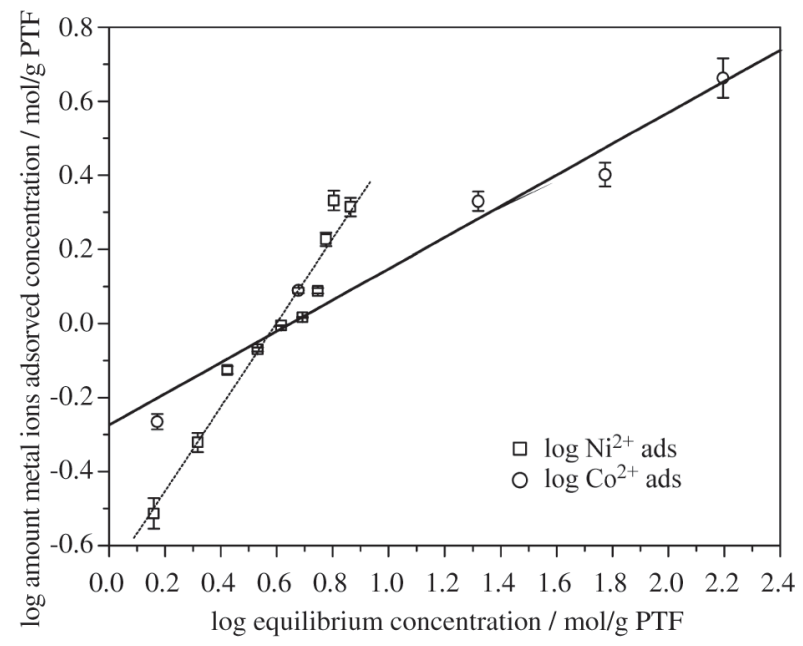

Figure 3. Adsorption Isotherm for metal ions $\mathrm{Ni} 2+$ and $\mathrm{Co} 2+$. 
Table 3. Results of the Freundlich isotherm plots at $35{ }^{\circ} \mathrm{C}$ and $\mathrm{pH}=6$.

\begin{tabular}{lcc}
\hline Metal ion & $\mathrm{K} \times 10^{-6}$ & $\alpha$ \\
\hline $\mathrm{Co}^{2+}$ & 5.32 & 0.421 \\
$\mathrm{Ni}^{2+}$ & 2.08 & 1.137 \\
\hline
\end{tabular}

Table 4. Maximum amount of ions adsorbed (mmol/g polymer) taken from isotherms and maximum sulfur content (mmol/g polymer) in the polymer as Thiol end group and as total sulfur.

\begin{tabular}{lccc}
\hline SH (Thiol) & Total sulfur & Co & $\mathrm{Ni}$ \\
\hline 0.39 & 8.9 & 0.045 & 0.022 \\
\hline
\end{tabular}

and $\mathrm{Ni}^{2+}$ ions. Particularly, the $\mathrm{Ni}^{2+}$ isotherm have associated an $\alpha$ Freundlich parameter value $(\alpha>1)$ characteristic of sorption process less favorable ${ }^{15}$ than $\mathrm{Co}^{2+}(\alpha<1)$ ions in the concentration range studied.

By the other hand the maximum amount adsorbed is less than the amount of thiol end groups present in the polymer sample (Table 4). This fact may be explained by means of a limited morphological access to whole volume.

\section{Conclusions}

The polythiofurfural yields could be increased up to $80 \%$ at $40{ }^{\circ} \mathrm{C}$. It was presented as an regular spheric particle which maintained the same solubility in an organic solvents, as those polymers obtained at low temperature $\left(30{ }^{\circ} \mathrm{C}\right)$.

These polythiofurfural resins presented a different affinity capacity to $\mathrm{Ni}$ (II) and $\mathrm{Co}$ (II) ions in aqueous solution and it opens a new potential aplication for furfuraldehyde resins with environmental impact for efluent treatment.

\section{Acknowledgements}

The authors thank CNPq to the financial support.

\section{References}

1. Barbucci, R.; Benvenuti, M.; Casolaro, M.; Billi, A. Polymer, v. 28, p. 969-976, 1987.

2. Sánchez, R.; Hernández, C.; Jalsovszky, G.; Czira, G. Eur. Polym. J., v. 30, n. 1, p. 37-42, 1994.

3. Sánchez, R.; Hernández, C.; Rosado, A; Fajardo, D. Rev. CENIC, Ciencias Químicas, v. 19, n.1-2-3, p. 50, 1988.

4. Sánchez, R.; Hernández C. Eur. Polym. J., v. 30, n. 1, p. 51-54, 1994.

5. Murroy, S.G.; Hartley, F.R. Concise Polymeric Materials Encyclopedia, Salomone, J.C., p. 1531, 1981.

6. Tsuda, K.; Yamashita, K. Supportes polythioethers and polthiacrown ethers, Concise Polymeric Encyclopedia, Salomone, J.C., p.1531, 1998.

7. Lago,R.; Ortiz, P.;Rieumont, J.; Sanchez, R. Polymer Bull., v. 41, p. 1-5, 1998.

8. Gandini, A. Advanced Polymer Science, v. 25, p. 83, 1977.

9. Lide, D.R. Handbook of Chemistry and Physics, $80^{\text {th }}$, p. 8-88, 1999.

10. Billmeyer, F.W. Textbook of Polymer Science, 3rd, Ed.Wiley \& Sons, New York, 1984.

11. Sanchez, R.; Martin, M.; Miguens, F.; Rieumont, J. Journal Colloidal and Interface Science, 17, v. 2, p. 111116, 1999.

12. Friebolin, H. Basic One and Two-dimensional Nuclear Magnetic Resonance Spectroscopy, 2nd, Ed. VCH Publish, New York, 1993.

13. Kaliyappan, T.; Swaminathan, C.S.; Kannan, P. Polymer, v. 37, n. 13, p. 2865, 1996.

14. Park, C.K.; Choi, M.J.; Lee, Y.M. Polymer, v. 36, n. 7, p. 1507, 1995.

15. Perry,R.H.; Chilton, C.H. Chemical Engineers Handbook, $5^{\text {th }}$. Ed. Section 16, International, Student Edition, Mc Graw Hill Kegakusha Ltd. Tokyo, 1973. 